\title{
Review
}

\section{A New Era: The Growth of Video-Based Visits for Remote Management of Persons with Parkinson's Disease}

\author{
Danielle N. Larson ${ }^{\mathrm{a}, 1}$, Ruth B. Schneider ${ }^{\mathrm{b}, \mathrm{c}, 1, *}$ and Tanya Simuni ${ }^{\mathrm{a}}$ \\ ${ }^{a}$ Department of Neurology, Northwestern University Feinberg School of Medicine, Chicago, IL, USA \\ ${ }^{\mathrm{b}}$ Department of Neurology, University of Rochester, Rochester, NY, USA \\ ${ }^{\mathrm{c}}$ Center for Health+Technology, University of Rochester, Rochester, NY, USA
}

Accepted 20 December 2020

Pre-press 20 January 2021

\begin{abstract}
The COVID-19 pandemic forced the abrupt and rapid expansion of an alternative care model that embraces the use of video-based visits in the care of persons with Parkinson's disease. Video-based visits not only eliminate the risk of infection but also reduce geography- and disability-related barriers to accessing specialist care. Research has established that they are feasible, acceptable to persons with Parkinson's disease and patient-centered. In the Unites States, the relaxation of licensure requirements, adoption of reimbursement parity and investment in telemedicine infrastructure has enabled the rapid growth of video-based visits during the COVID-19 pandemic. Now, we must turn our attention to ensuring that progress made in expanding access to video-based care is not lost and expanded worldwide. More work is needed to identify the optimal video-based care model, establish best practices, and ensure equitable access to care.
\end{abstract}

Keywords: Parkinson's disease, telemedicine, remote consultation, coronavirus

\section{INTRODUCTION}

Over 6 million individuals worldwide have Parkinson's disease (PD) [1] and the prevalence is rapidly increasing, with the number affected by PD expected to double by 2040 [2]. Neurologist care improves outcomes for persons with PD [3, 4] yet access to neurologist care is limited in many areas $[4,5]$ due to the uneven geographic distribution of neurologists $[5,6]$. Access to care is also limited by PD-related disability [7] and driving impairment [8], which can impede travel to clinic. A better model of care is needed in

\footnotetext{
${ }^{1}$ These authors contributed equally to this work.

*Correspondence to: Ruth Schneider, MD, Box MIND, University of Rochester, 265 Crittenden Blvd, Rochester, NY 14642, USA. Tel.: +1 585273 1856; E-mail: ruth_schneider@ urmc.rochester.edu.
}

order to meet the growing demand for neurologist care for persons with PD. Telemedicine, which includes the use of real-time video-conferencing between healthcare providers and persons with PD for clinical care (video-based visits), represents one such advancement in care. By bringing care directly into the home, video-based visits can improve access to care in a patient-centered manner that minimizes the burden on persons with PD and their care partners. The ongoing COVID-19 pandemic, which has resulted in the death of over 1,400,000 people worldwide [9], has created new and urgent impetus to identify alternatives to traditional in-person care. This is particularly relevant for those with advanced PDassociated frailty who may have a higher COVID-19 mortality rate [10]. Here, we review the use of videobased visits for the management of persons with PD 
and future directions. The review focuses on North America and provides a high-level overview of experiences worldwide.

\section{VIDEO-BASED VISITS IN THE CARE OF PERSONS WITH PD}

The largely visual nature of the PD examination lends itself well to video-based visits. In-home videobased visits are feasible with visit completion rates exceeding 90\% (Table 1) [11, 12]. A modified version of the Movement Disorder Society - Unified Parkinson Disease Rating Scale (MDS-UPDRS) motor examination, excluding assessment of rigidity and postural instability, can be administered remotely [13]. In an analysis of more than 550 video-based PD research visits, $98 \%$ of modified MDS-UPDRS motor items were successfully rated [14]. While agreement between video-based and in-person modified MDSUPDRS motor scores is only moderate [15], this is unlikely to affect clinical care. Common cognitive assessments, including the Montreal Cognitive Assessment, can be administered remotely in PD [16], however, validation is needed. The inability to obtain a complete neurological examination may limit the utility of video-based visits in the care of individuals without an established diagnosis.

Video-based visits are well-received by persons with PD with high overall satisfaction rates (94-97\%) $[11,12]$ and particular appreciation for the convenience and comfort afforded [17]. Video-based visits are also associated with substantial patient timeand travel-savings $[11,12]$. Patient interest is corre-

Table 1

Current State of Video-Based Visits for PD Care

\begin{tabular}{lccc}
\hline & Established & In Progress & Needed \\
\hline Feasibility & $\checkmark$ & & \\
Patient Satisfaction & $\checkmark$ & & \\
Provider Satisfaction & & $\checkmark$ & \\
Validation of & & $\checkmark$ & \\
$\quad$ Motor Examination & & & \\
Validation of & & & \\
$\quad$ Cognitive Examination & & & \\
Management of & & & \\
$\quad$ Advanced Therapies & & & \\
Feasibility of & $\checkmark$ & & \\
$\quad$ Psychiatric Care & & & \\
Feasibility of & $\checkmark$ & & \\
$\quad$ Rehabilitative & & & \\
$\quad$ Therapy Services & & & \\
Model for & & & \\
$\quad$ Interdisciplinary Care & &
\end{tabular}

spondingly high; in a survey-based study of over 700 persons with $\mathrm{PD}, 77 \%$ indicated interest in videobased visits with a PD specialist [18]. Pre-COVID, physician satisfaction with [12] and enthusiasm for video-based visits was more tempered, with concerns relating to the technical aspects of visits [17]. Similarly, only $40 \%$ of local physicians $(n=89)$ for participants in a trial of video-based visits for PD indicated that they would recommend video-based visits with a PD specialist, potentially reflecting poor communication of recommendations [19]. While concerns regarding the ability to establish a personal connection have been raised, in many ways videobased visits afford greater intimacy and insight into a patient's life.

Beyond potentially improving access, video-based visits can be used to deliver tele-rehabilitation services (discussed elsewhere in this special issue), provide psychiatric care, and manage advanced therapies. Follow-up video-based psychiatry care for persons with PD is feasible, improves access to psychiatric care, and is associated with high rates of satisfaction [20]. In a randomized, controlled trial of telephone-based cognitive behavioral therapy (CBT) plus usual care versus usual care for depression in PD $(n=72)$, the treatment group demonstrated a significant improvement in depressive symptoms at treatment end that was maintained long-term [21]. A study of video-based CBT for PD depression has been completed but not yet published (clinicaltrials.gov NCT02475954). The feasibility of video-based CBT for PD anxiety $(n=9)$ was demonstrated in a recent pilot study [22]. While many procedures cannot be performed remotely, video-based visits can facilitate the management of advanced therapies, including initial titration of levodopa-carbidopa intestinal gel [23], pre-surgical screening of deep brain stimulation candidates [24], and adjustments in deep brain stimulation settings [25].

However, large studies examining the value of usual care plus video-based visits with PD specialists have failed to show an improvement in quality of life. In a large cohort study, PD participants $(n=277)$ received a one-time in-home video-based visit with a PD specialist with no significant improvement in quality of life at 6 months [11]. Similarly, in a large, randomized controlled study, PD participants $(n=195)$ were randomized to usual care versus usual care plus video-based visits with a PD specialist and no between group differences in change in quality of life, caregiver burden, quality of care, or healthcare utilization from baseline to month 12 were identified 
[12]. The lack of improvement in quality of life may have reflected high baseline access to PD specialist care $(59-73 \%)$ in the tested cohort and reliance on local physicians to implement recommendations.

\section{COVID-19 PROPELLED RAPID CHANGES IN THE TELEMEDICINE PRACTICE LANDSCAPE}

While some established telemedicine networks existed pre-COVID (e.g., Ontario Telemedicine Network, U.S. Department of Veterans Affairs), variable rates of internet access, licensure requirements, and reimbursement barriers limited widespread implementation of video-based visits in the care of persons with PD. In the U.S., only $59 \%$ of adults $\geq 65$ years old have home broadband access; Black and Hispanic/Latino individuals and those with lower education levels, lower income levels, and rural residence are less likely to have access [26]. Pre-COVID, Medicare, which insures roughly 60 million Americans over age 65 [27], did not reimburse for in-home video-based visits for persons with PD [28] and only approximately $40 \%$ of states allowed for Medicaid reimbursement for in-home video-based visits [29]. The COVID-19 pandemic has forced the rapid adoption of video-based visits [30] and exponential growth of publications $(n=59$ posted on PubMed in 2020). Telemedicine visits in March of 2020 surged $50 \%$ and Medicare primary care video-based visits increased from $1 \%$ in February to nearly $50 \%$ in April 2020 [31, 32]. Spurred by necessity, changes in policy, infrastructure, technology, and social opinion have resulted in broad changes in the telemedicine practice landscape [33]. The International Parkinson and Movement Disorders Society (MDS) Telemedicine Study Group highlighted the need for ongoing updates of telemedicine guidelines and regulatory policies worldwide and has developed a practical guide for telemedicine visits [34, 35].

\section{Policy changes}

This section focuses on the U.S.-based experience as country policies vary widely. U.S. governmental regulations and payer-driven reimbursement policies were expeditiously modified. Congress allocated $\$ 500$ million to support telemedicine services; Department of Health and Human Services (HHS) and Centers for Medicare and Medicaid Services (CMS) eased restrictions on telemedicine and revised reimbursement policies [36]. Medicare changes included expansion of service coverage and removal of licensing barriers. Specific changes included the addition of coverage for 1) new patient video-based visits (eliminating the requirement for a pre-existing relationship), 2) in-home video-based visits, and 3) other services, including psychiatry and rehabilitative therapies. In addition, Medicare waived the previous requirement that the clinician must be licensed in the same state as the patient's residence. With parity in Current Procedural Terminology codes, payments for video-based visits now match those for faceto-face visits [37]. HHS enabled Health Insurance Portability and Accountability Act (HIPAA) flexibility with respect to platform use, allowing providers to use readily available applications, such as Skype, Microsoft Teams, Doximity, and Zoom, as long as they are not public-facing (i.e., Facebook Live) [38].

\section{Infrastructure changes}

In response to loosened governmental policy regulations, infrastructure for telemedicine has been expeditiously implemented and augmented across healthcare systems. This has required a rapid scaleup of information technology (IT) infrastructure, including on-boarding platforms, troubleshooting platforms and in-servicing providers. New York University's ability to implement a robust IT framework was integral to their swift development of a virtual neurology program [39].

Increased investment in telemedicine services has supported the immense growth in telemedicine. Telemedicine service companies have seen a $175 \%$ increase in customers [40]. There are now 45 prominent healthcare-specific virtual platforms, including Zoom for Healthcare and Doximity Dialer Video [41]. Many vendors are adapting to healthcare's specific needs, such as through HIPAA business associate agreements $[42,43]$. The U.S. telehealth market is projected to experience a year-over-year increase of $64.3 \%$ in 2020 , and seven-fold growth by 2025 [44].

In parallel, there has been an increase in patient and community interest in telehealth. In a survey of 1,800 adults, $55 \%$ were willing to use video-based visits to see new doctors, and $83 \%$ said they would likely continue to use telemedicine after the pandemic [45]. The percentage of US consumers replacing in-person visits with video-based visits has increased from $11 \%$ in 2019 to $46 \%$ [37]. Web-based resources, including webinars, virtual exercise classes and support groups, 
reflects growing patient and community familiarity and comfort with video-based technology [46].

\section{WORLDWIDE TELEMEDICINE EXPERIENCE}

Considering that telemedicine is highly dependent on the availability of technology and country-specific policies, adoption of telemedicine care delivery has been very variable across the globe. Regarding the care of advanced PD in the setting of COVID-19, Fasano et al reported international clinicians' overall lack of preparedness to deliver virtual care and limited telemedicine platforms [47]. The authors highlighted the need for rapid adoption of remote care delivery models and expanded use of digital technology for remote patient monitoring, while providing algorithms to remotely care for deep brain stimulation, levodopa/ carbidopa intestinal gel infusions and other advanced therapies. Similarly, the Digital Technologies, Web and Social Media Study Group of the Italian Society of Neurology published a review of remote PD care delivery in the setting of COVID-19 pandemic that includes a battery of tests for telemedicine visits, patient reported outcomes and smartphone applications [48]. Additionally, the MDS Telemedicine Study Group developed a practical guide on how to implement telemedicine visits, though it does not address regional policies and technology limitations [35].

\section{FUTURE DIRECTIONS}

Action needs to be taken to ensure that the immense strides in adopting telemedicine for neurologic care during the COVID-19 pandemic are sustainable, and to improve access to care and quality of care (Fig. 1).

\section{Sustainable and equitable access}

Policy changes, including reimbursement parity and relaxation of licensing requirements, need to be maintained through governmental advocacy; the American Academy of Neurology (AAN) is leading this effort on behalf of the neurology community [49]. A concerted effort is needed to ensure equitable access to telemedicine for underserved, rural, and nursing home communities. Special emphasis should be made on access to care in underdeveloped countries. As telemedicine expands, the "digital divide" driven largely by socioeconomic determinants of health, persists [50]. In a cross-sectional study, individuals living in a neighborhood of lower socioeconomic status were significantly less likely to choose a video-based primary care visit (RRR 0.93; 95\% CI, 0.89-0.97) compared to those living in a neighborhood with higher socio-economic status. Similarly, individuals with a non-English language preference were significantly less likely to choose a video-based visit compared to those with an English language preference [51]. Thus, there is concern that

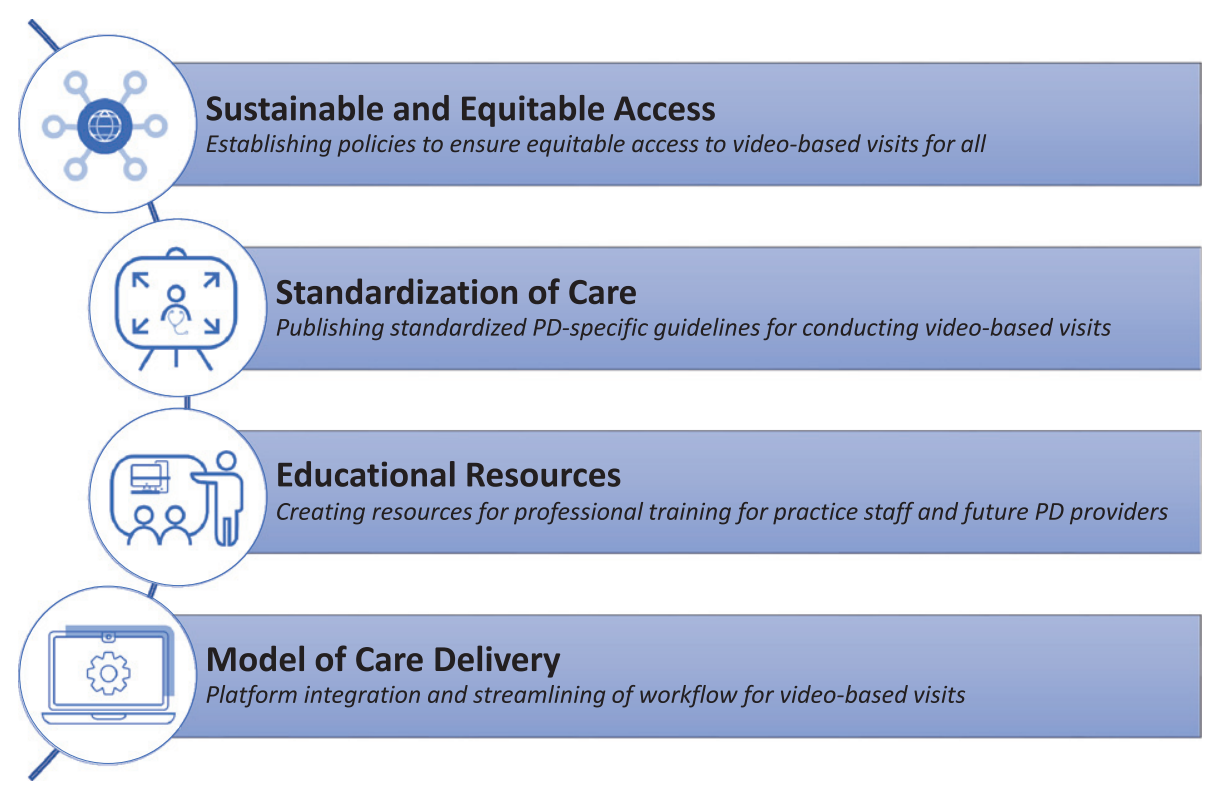

Fig. 1. Future Directions for Video-Based Visits for PD Care. 
pre-existing disparities in access to neurologist care for persons with PD could widen in a primary videobased-visit model of care as long as these inequities persist [4]. Policies must be written, and funding allocated accordingly, to address these disparities before the digital divide widens, and the gap in PD care along with it. Telemedicine affords tremendous opportunity for cross-country care delivery - specifically for underdeveloped countries - provided the technology is available.

\section{Standardization of care}

Professional organizations, including the AAN, are introducing care guidelines, from conducting a neurologic examination to billing and coding practices [52]. While MDS has created a "step-by-step" guide for telemedicine practice, it does not cover regional differences and regulations [53]. Next steps should include the development of standardized guidelines for PD-specific virtual examination techniques. Validation of the modified MDS-UPDRS motor examination would help to enable uniformity of PD care delivery. A standardized method of video-based interdisciplinary PD care delivery incorporating, for example, social work, nutrition, and nursing, could augment care and potentially "outperform" in-person visits by providing increased access to ancillary services in the home environment.

\section{Educational resources}

Resources for professional training need to extend to practice staff and future providers. Recognizing this need, the AAN Telemedicine Work Group published the first model framework for a teleneurology curriculum for neurology residents in 2017 [54]. This occurred in parallel with a pilot outpatient teleneurology resident curriculum at the University of California San Francisco, which improved resident knowledge and competence in using telemedicine in future practice [55].

\section{Model of care delivery}

As telemedicine platforms are integrated into clinical practices, healthcare systems will need to streamline the workflow of virtual encounters, from accurate medication reconciliation to scheduling follow-up appointments. Integration of the telemedicine platform into the electronic medical record can simplify visits and reduce administrative burden, particularly in the delivery of interdisciplinary care. Providing instructions to patients in advance is also integral to ensuring efficiency and satisfaction.

\section{CONCLUSIONS}

Video-based visits uniquely provide what has been aptly described as "the four C's" for PD patients: care, convenience, comfort, and confidentiality [56]. The COVID-19 pandemic has added a $5^{\text {th }} \mathrm{C}$, contagion, which accelerated the adoption of video-based visits through changes in policy and regulation, precipitous advancement of technology and infrastructure, increased patient interest, and greater acceptance of this novel care model. We must now deliver on the promise of video-based visits to improve access to, and further enhance the quality of PD care. Advocating for continued policy changes and equitable access, as well as establishing best practices for video-based care, must be a top priority for PD pro viders and health systems world-wide. Telemedicine offers a unique opportunity to propel PD patient care into the $21^{\text {st }}$ century with a novel philosophy and platform of patient-centric care delivery. However, achieving this ambitious but realistic goal will require ongoing collaborative efforts between the international movement disorders community, policy makers, and patients, extending beyond the COVID19 crisis.

\section{ACKNOWLEDGMENTS}

Dr. Schneider receives research support from National Institutes of Health, Michael J. Fox Foundation for Parkinson's Research, Biohaven Pharmaceuticals, Acadia Pharmaceuticals, and the CHDI Foundation.

Dr Danielle Larson receives research support from the Parkinson's Foundation, Huntington's disease Society of America (HDSA), Acadia Pharmaceuticals.

Dr. Tanya Simuni receives grant support from the National Institutes of Health, Michael J. Fox Foundation for Parkinson's Research, Parkinson's Foundation, grants from Biogen, Roche, Neuroderm, Sanofi, Sun Pharma, Abbvie, IMPAX, Prevail, consulting from Acadia, Abbvie, Accorda, Adamas, Allergan,Amneal, Aptinyx, Denali, General Electric (GE), Kyowa, Neuroderm, Neurocrine, Sanofi, Sinopia, Sunovion, Roche, Takeda, Voyager, US World Meds. 


\section{CONFLICT OF INTEREST}

The authors have no conflict of interest to report.

\section{REFERENCES}

[1] GBD 2016 Parkinson's Disease Collaborators (2018) Global, regional, and national burden of Parkinson's disease 1990-2016: A systematic analysis for the Global Burden of Disease Study 2016. Lancet Neurol 17, 939-953.

[2] Dorsey ER, Bloem BR (2018) The Parkinson pandemic A call to action. JAMA Neurol 75, 9-10.

[3] Willis AW, Schootman M, Tran R, Kung N, Evanoff BA, Perlmutter JS, Racette BA (2012) Neurologist-associated reduction in PD-related hospitalizations and health care expenditures. Neurology 79, 1774-1780.

[4] Willis AW, Schootman M, Evanoff BA, Perlmutter JS, Racette BA (2011) Neurologist care in Parkinson disease: A utilization, outcomes, and survival study. Neurology 77, 851-857.

[5] Lim S, Tan AH, Ahmad-Annuar A, Klein C, Tan LCS, Rosales RL, Bhidayasiri R, Wu Y, Shang H, Evans AH, Pal PK, Hattori N, Tan CT, Jeon B, Tan E, Lang AE (2019) Parkinson's disease in the Western Pacific region. Lancet Neurol 18, 865-879.

[6] Dall TM, Storm MV, Ritashree C, Drogan O, Keran CM, Donofrio PD, Henderson VW, Kaminski HJ, Stevens JC, Vidic TR (2013) Supply and demand analysis of the current and future US neurology workforce. Neurology 81, 470-478.

[7] Shulman LM, Gruber-Baldini AL, Anderson KE, Vaughan CG, Reich SG, Fishman PS, Weiner WJ (2008) The evolution of disability in Parkinson disease. Mov Disord 23, 790-796.

[8] Ranchet M, Devos H, Uc EY (2020) Driving in Parkinson disease. Clin Geriatr Med 36, 141-148.

[9] World Health Organization, WHO Coronavirus Disease (COVID-19) Dashboard, https://covid19.who.int/, Accessed on November 29, 2020.

[10] Fasano A, Elia AE, Dallocchio C, Canesi M, Alimonti D, Sorbera C, Alonso-Canovas A, Pezzoli G (2020) Predictors of COVID-19 outcome in Parkinson's disease. Parkinsonism Relat Disord 78, 134-137.

[11] Korn RE, Wagle SA, Katz M, Keenan HT, Goldenthal S, Auinger P, Zhu W, Dodge M, Rizer K, Achey MA, Byrd E, Barbano R, Richard I, Andrzejewski KL, Schwarz HB, Dorsey ER, Biglan KM, Kang G, Kanchana S, Rodriguez R, Tanner CM, Galifianakis NB (2017) Virtual visits for Parkinson disease: A multicenter noncontrolled cohort. Neurol Clin Pract 7, 283-295.

[12] Beck CA, Beran DB, Biglan KM, Boyd CM, Dorsey ER, Schmidt PN, Simone R, Willis AW, Galifianakis NB, Katz M, Tanner CM, Dodenhoff K, Aldred J, Carter J, Fraser A, Jiminez-Shahed J, Hunter C, Spindler M, Reichwein S, Mari Z, Dunlop B, Morgan JC, McLane D, Hickey P, Gauger L, Richard IH, Mejia NI, Bwala G, Nance M, Shih LC, Singer C, Vargas-Parra S, Zadikoff C, Okon N, Feigin A, Ayan J, Vaughan C, Pahwa R, Dhall R, Hassan A, DeMello S, Riggare SS, Wicks P, Achey M, Elson MJ, Goldenthal S, Keenan HT, Korn R, Schwarz H, Sharma S, Stevenson EA, Zhu W; Connect.Parkinson Investigators (2017) National randomized controlled trial of virtual house calls for Parkinson disease. Neurology 89, 1152-1161.
[13] Dorsey ER, Wagner JD, Bull MT, Rizzieri A, Grischkan J, Achey MA, Sherer T, Chowdhury S, Meunier C, Cappelletti L, Rocker C, Richard IH, Schwarz H, Kang G, Ahmad SH, Biemiller RA, Biglan KM (2015) Feasibility of virtual research visits in Fox Trial Finder. J Parkinsons Dis $\mathbf{5}$, 505-515.

[14] Schneider RB, Myers TL, Tarolli CH, Amodeo K, Adams JL, Jensen-Roberts S, Dorsey ER (2020) Remote administration of the MDS-UPDRS in the time of COVID-19 and beyond. J Parkinsons Dis 10, 1379-1382.

[15] Tarolli CG, Andrzejewski K, Zimmerman GA, Bull M, Goldenthal S, Auinger P, O’Brien M, Dorsey ER, Biglan K, Simuni T (2020) Feasibility, reliability, and value of remote video-based trial visits in Parkinson's disease. J Parkinsons Dis 10, 1779-1786.

[16] Stillerova T, Liddle J, Gustafsson L, Lamont R, Silburn P (2016) Could everyday technology improve access to assessments? A pilot study on the feasibility of screening cognition in people with Parkinson's disease using the Montreal Cognitive Assessment via internet videoconferencing. Aust Occup Ther J 63, 373-380.

[17] Mammen JR, Elson MJ, Java JJ, Beck CA, Beran DB, Biglan KM, Boyd CM, Schmidt PN, Simone R, Willis AW, Dorsey ER (2018) Patient and physician perceptions of virtual visits for Parkinson's disease: A qualitative study. Telemed $J E$ Health 24, 255-267.

[18] Spear KL, Auinger P, Simone R, Dorsey ER, Francis J (2019) Patient views on telemedicine for Parkinson disease. J Parkinsons Dis 9, 401-404.

[19] Elson MJ, Stevenson EA, Feldman BA, Lim J, Beck CA, Beran DB, Schmidt PN, Biglan KM, Simone R, Willis AW, Dorsey ER, Boyd CM (2018) Telemedicine for Parkinson's disease: Limited engagement between local clinicians and remote specialists. Telemed J E Health 24, 722-724.

[20] Seritan AL, Heiry M, Iosif AM, Dodge M, Osterm JL (2019) Telepsychiatry for patients with movement disorders: A feasibility and patient satisfaction study. J Clin Mov Disord 6,1 .

[21] Dobkin RD, Mann SL, Gara MA, Interian A, Rodriguez KM, Menza M (2020) Telephone-based cognitive behavioral therapy for depression in Parkinson disease: A randomized controlled trial. Neurology 94, e1764-e1773.

[22] Reynolds GO, Saint-Hilaire M, Thomas CA, Barlow DH, Cronin-Golomb A (2020) Cognitive-behavioral therapy for anxiety in Parkinson's disease. Behav Modif 44, 552-579.

[23] Willows T, Dizdar N, Nyholm D, Widner H, Grenholm P, Schmiauke U, Urbom A, Groth K, Larsson J, Permert J, Kjellander S (2017), Initiation of levodopa-carbidopa intestinal gel infusion using telemedicine (video communication system) facilitates efficient and well-accepted home titration in patients with advanced Parkinson's disease. $J$ Parkinsons Dis 7, 719-728.

[24] Witek N, Heath SL, Ouyang B, Tanner CM, Galifianakis NB (2020) Remote telemedicine evaluation of deep brain stimulation candidacy: Retrospective cohort analysis. Neurol Clin Pract 10, 199-205.

[25] Jitkritsadakul O, Rajalingam R, Toenjes C, Munhoz RP, Fasano A (2018) Tele-health for patients with deep brain stimulation: The experience of the Ontario Telemedicine Network. Mov Disord 33, 491-492.

[26] Pew Research Center, Internet/Broadband Fact Sheet, https://www.pewresearch.org/internet/fact-sheet/internetbroadband/, Last updated June 12, 2019, Accessed on September 15, 2020. 
[27] Kaiser Family Foundation, An Overview of Medicare, https://www.kff.org/medicare/issue-brief/an-overview-ofmedicare/, Last updated February 13, 2019, Accessed on September 23, 2020.

[28] Centers for Medicare \& Medicaid Services, Telehealth Services, https://www.cms.gov/Outreach-and-Education/Med icare-Learning-Network-MLN/MLNProducts/Downloads/ TelehealthSrvcsfctsht.pdf, Last updated March 2020, Acc essed on September 15, 2020.

[29] Center for Connected Health Policy, State Telehealth Laws \& Reimbursement Policies, https://www.cchpca.org/sites/ default/files/2020-05/CCHP_\%2050_STATE_REPORT_SP RING_2020_FINAL.pdf, Last updated spring 2020, Acc essed on September 15, 2020.

[30] Bloem BR, Dorsey RE, Okun M (2020) The coronavirus disease 2019 crisis as catalyst for telemedicine for chronic neurological disorders. JAMA Neurol 77, 927-928.

[31] Coombs B, Telehealth visits are booming as doctors and patients embrace distancing amid the coronavirus crisis, CNBC, https://www.cnbc.com/2020/04/03/telehealth-visit $\% 20$ s-could-top-1-billion-in-2020-amid-the-coronaviruscrisis.html, Last updated April 4, 2020, Accessed on September 15, 2020.

[32] HHS Issues New Report Highlighting Dramatic Trends in Medicare Beneficiary Telehealth Utilization amid COVID19, https://telehealth.hhs.gov/, Last updated July 28 2020, Accessed on September 15, 2020.

[33] Papa SM, Brundin P, Fung VSC, Kang UJ, Burn DJ, Colosimo C, Chiang HL, Alcalay RN, Trenkwalder C; MDS-Scientific Issues Committee (2020) Impact of the COVID-19 pandemic on Parkinson's disease and movement disorders. Mov Disord Clin Pract 7, 357-360.

[34] Telemedicine in your movement disorders practice. https:// www.movementdisorders.org/MDS/About/CommitteesOtherGroups/Telemedicine-in-Your-MovementDisordersPractice-A-Step-by-Step-Guide.html, updated April 2020, Accessed on November 11, 2020.

[35] Cubo E, Hassan A, Bloem BR, Mari Z; MDS-Telemedicine Study Group (2020) Implementation of telemedicine for urgent and ongoing healthcare for patients with Parkinson's disease during the COVID-19 pandemic: New expectations for the future. J Parkinsons Dis 10, 911-913.

[36] Redford G, Delivering more care remotely will be critical as COVID-19 races through communities, AAMC, https:// www.aamc.org/news-insights/delivering-more-care-remo te\%20ly-will-be-critical-covid-19-races-through-commun ities, Last updated March 23, 2020, Accessed on September 15, 2020.

[37] Billing and reimbursement during the COVID-19 public health emergency https://telehealth.hhs.gov/providers/bill ing-and-reimbursement/?section=1,2,4\#billing-medicarefor-fee-for-service-telehealth, Last updated September 11, 2020, Accessed on September 15, 2020.

[38] Policy changes during the COVID-19 Public Health Emer gency. https://telehealth.hhs.gov/providers/policy-changesduring-the-covid-19-public-healthemergency/\#incorporating-newly-allowed-technologydue-to-hipaa-flexibility, Last updated September 22, 2020, Accessed on September 23, 2020.

[39] Grossman SN, Han SC, Balcer LJ, Kurzweil A, Weinberg H, Galetta SL, Busis NA (2020) Rapid implementation of virtual neurology in response to the COVID-19 pandemic. Neurology 94, 1077-1087.

[40] Telehealth: A quarter-trillion-dollar post-COVID-19 reality? McKinsey \& Company Healthcare Systems \& Services. https://www.mckinsey.com/industries/healthcare-systemsand-services/our-insights/telehealth-a-quarter-trilliondollar-post-covid-19-reality, Last updated May 29, 2020, Accessed on September 14, 2020.

[41] US Telehealth market sees an increase in demand for telehealth services due to COVID-19 pandemic, Businesswire.com, https://www.businesswire.com/news/home/20 200427005249/en/Telehealth-Market-Sees-Increase-

Demand-Telehealth-Services, Last updated April 27, 2020, Accessed on September 15, 2020.

[42] Doximity launces dialer video, https://www.doximity.com/ press_releases/doximity_launches_dialer_video?_remember _me_attempted=yes, Last Updated May 5, 2020, Accessed on September 20, 2020

[43] Zoom for Healthcare, https://zoom.us/healthcare, Accessed on September 20, 2020

[44] Fernandez, M. Telehealth to experience massive growth with covid-19 pandemic, says Frost \& Sullivan. https://ww2. frost.com/news/press-releases/telehealth-to-experience-ma ssive-growth-with-covid-19-pandemic-says-frost-sullivan/ \#: :text=\%E2\%80\%93\%20May\%2013\%2C\%202020\%20\% E2\% $80 \% 93 \% 20$ Frost,and $\% 20$ the $\% 20$ delivery $\% 20$ of $\% 20$ healthcare, Last updated May 13, 2020, Accessed on September 20, 2020.

[45] The future of healthcare: Patient perceptions, preferences, and adoption of telemedicine, Doctor.com https://www. doctor.com/resources/telemedicine, Accessed on September 15,2020 .

[46] Virtual Programs and Events available to support PD community through ongoing COVID-19 pandemic, Practical Neurology, https://practicalneurology.com/news/virtual-pr ograms-and-events-available-to-support-pd-community-th rough-ongoing-covid-19-pandemic?c4src=home $\% 3$ Aside bar, Last updated August 26, 2020, Accessed on September 14, 2020.

[47] Fasano A, Antonini A, Katzenschlager R, Krack P, Odin P, Evans AH, Foltynie T, Volkmann J, Merello M (2020) Management of advanced therapies in Parkinson's disease patients in times of humanitarian crisis: The COVID-19 experience. Mov Disord Clin Pract 7, 361-372.

[48] Miele G, Straccia G, Moccia M, Leocani L, Tedeschi G, Bonavita S, Lavorgna L, Digital Technologies, Web and Social Media Study Group of the Italian Society of Neurology (2020) Telemedicine in Parkinson's disease: How to ensure patient needs and continuity of care at the time of COVID-19 pandemic. Telemed J E Health 26, 1533-1536.

[49] Covid-19 neurology resource center: Advocacy in action. https://www.aan.com/tools-and-resources/covid-19-neurol ogy-resource-center/advocacy/, Accessed on September $15,2020$.

[50] Norris P (2001) Digital Divide: Civic Engagement, Information Poverty, and the Internet Worldwide (Communication, Society and Politics), Cambridge University Press.

[51] Reed M., Huang J, Graetz I, Lee C, Muelly E, Kennedy C, Kim E (2020) Patient characteristics associated with choosing a telemedicine visit vs. office visit with the same primary care clinicians. JAMA Netw Open 3, e205873.

[52] Telemedicine and Remote Care, American Academy of Neurology, https://www.aan.com/tools-and-resources/pract icing-neurologists-administrators/telemedicine-and-remo te-care, Accessed on September 2, 2020.

[53] Telemedicine Study Group, Resources and References, International Parkinson and Movement Disorder Society, https://www.movementdisorders.org/MDS/About/Commi 
ttees-Other-Groups/Telemedicine-in-Your-Movement-

Disorders-Practice-A-Step-by-Step-Guide/Resources-andReferences.html, Accessed on August 20, 2020.

[54] Govindarajan R, Anderson ER, Hesselbrock RR, Madhavan R, Moo LR, Mowzoon N, Otis J, Rubin MN, Soni M, Tsao JW, Vota S, Planalp H (2017) Developing an outline for teleneurology curriculum: AAN Telemedicine Work Group recommendations. Neurology 89, 951-959.
[55] Afshari M, Witek NP, Galifianakis NB (2019) Education research: An experiential outpatient teleneurology curriculum for residents. Neurology 93, 170-175.

[56] Dorsey ER, Okun MS, Bloem BR (2020) Care, convenience, comfort, confidentiality, and contagion: The $5 \mathrm{C}$ 's that will shape the future of telemedicine. J Parkinsons Dis 10, 893897. 